\title{
O ESTADO DE EXCEÇÃO E A ESTRUTURA ORIGINÁRIA DA SOBERANIA EM GIORGIO AGAMBEN ${ }^{1}$
}

\section{Estenio Ericson Botelho Azevedo (UECE) ${ }^{2}$}

estenio.ericson@uece.br

\begin{abstract}
Talvez fosse mais justo reconhecer nele [no campo] uma angústia atávica, aquela cujo eco se sente no segundo versículo do Gênese: $a$ an-

gústia - inscrita em cada qual - do tòhu vavòhu, do universo deserto e vazio, esmagado sob o espirito de Deus, mas do qual o espírito do homem está ausente: ainda não nascido ou já extinto.

(Primo Levi, Os afogados e os sobreviventes)
\end{abstract}

Resumo: Partindo da conexão categorial entre o campo e o estado de exceção, proponho-me a discutir neste artigo a concepção de Giorgio Agamben sobre o estado de exceção em sua relação paradoxal com o direito, relação esta que é própria à estrutura paradoxal da soberania. O campo é para o pensador italiano a experiência capaz de esclarecer a dimensão paradoxal do estado de exceção porque ele se expressa, ao mesmo tempo, como fora e dentro do ordenamento jurídico. Na experiência contemporânea o estado de exceção se não caracteriza mais como uma experiência excepcional, mas tornou-se normal. Com base nisso, buscamos indicar o diálogo de Agamben com Carl Schmitt, com vistas a refletir sobre essa condição do estado de exceção de se apresentar como anomia, sem contudo deixar de estabelecer com a lei uma necessária relação, mesmo que na forma da suspensão.

Palavras-chave: Campo; Soberania; Estado de Exceção; Força-de-lei.

\section{VIDA NUA, ESTADO DE EXCEÇÃO E CAMPO}

Com a categoria de vida nua, Agamben busca relacionar

\footnotetext{
${ }^{1}$ Recebido: 07-02-2014/Aprovado: 17-06-2014/Publicado on-line: 08-09-2014.

${ }^{2}$ Estenio Ericson Botelho Azevedo é Professor Doutor da Universidade Estadual do Ceará, Fortaleza, Ceará, CE, Brasil.
} 
soberania e biopolítica, estado de exceção e campo. Para ele, o campo de concentração é a experiência propriamente contemporânea em que a vida nua se manifesta ao extremo, o lugar no qual o poder sobre a vida (ou biopoder) chega às suas últimas consequências. $\mathrm{O}$ campo é definido por Agamben (2001, p. 175) como "o espaço que se abre quando o estado de exceção começa a tornar-se a regra". O estado de exceção produz o campo. Este é, assim, um dispositivo que só pode ser pensado com base na estrutura do estado de exceção, na (ex)posição de uma abertura, de um vacum na normatividade, que não é, por isso, efetivamente ausência de normatividade. Em outras palavras, pensar o campo exige que este seja concebido com fundamento na suspensão legal do dispositivo legal, constituindo, por meio disso, uma situação político-jurídica excepcional. Embora alguns judeus que iam para o campo de concentração durante o regimente concentracionário alemão, assim $\mathrm{o}$ faziam espontaneamente, "absurdamente, para 'ficarem dentro da lei'", 3 como destaca Primo Levi, o campo mantém, como produto do estado de exceção, uma relação de exclusão (ou de exceção) com relação à lei; ele é, de certa forma, a sua inexecução. Mas, de algum modo, não por acaso, aqueles que se lhe submeteram para se coadunar com a lei, não se equivocaram de todo:

Na medida em que o estado de exceção é, de fato, 'desejado', ele inaugura um novo paradigma jurídico-político, no qual a norma torna-se indiscernível da exceção. O campo é, digamos, a estrutura em que o estado de exceção, em cuja possível decisão se baseia o po-

\footnotetext{
${ }^{3}$ Falando do primeiro campo de concentração em que foi prisioneiro (o de Fóssoli, ainda na Itália), Levi (1988, p. 12) relata: "Havia também uns poucos [judeus] que se tinham apresentado espontaneamente, devido ao desespero de continuarem vivendo errantes e fugidios, ou por terem ficado sem recurso algum, ou por não quererem separar-se de um parente já detido, ou ainda, absurdamente, para 'ficarem dentro da lei”.
} 
der soberano, é realizado normalmente (AGAMBEN 2001, P. 177).

No campo, o normal já não é a regra, mas a exceção. Ele não é apenas uma situação fora da norma, mas enquanto tal é a situação em que o normal se torna essa ausência de normatividade, o momento e o lugar em que fato e direito se tornam indiscerníveis. Dito de outro modo, essa é uma situação na qual, e em consequência da qual, norma e exceção se indistinguem. A elucidação dessa estrutura de indistinção é fundamental para que então se torne mais clara a compreensão do estado de exceção na reflexão do referido pensador italiano, bem como sua análise acerca da decisão soberana na política contemporânea e da crise do próprio direito com uma visão histórica mais ampla: "A estrutura da exceção [...] parece ser, nesta perspectiva, consubstancial à política ocidental" (IDEM, p. 15).

Agamben chama a atenção para o fato de a exceção não poder ser pensada simplesmente como uma situação fora (excluída), mas como uma exclusão inclusiva (exceptio). Para ele, a exceptio constitui de modo decisivo a relação entre política e vida, desde os gregos. $\mathrm{O}$ modo da relação entre zoé (vida natural) e bios (forma de vida, política) se efetiva por meio de uma exclusão inclusiva. Não é necessário retomar aqui essa questão, já bastante discutida pelos comentadores de Agamben, ${ }^{4}$ mas com base nela considerar que, mesmo a

\footnotetext{
${ }^{4}$ Cabe dizer que na sua apresentação desta exclusão inclusiva sob a forma da relação entre vida nua e forma de vida, Agamben faz uma análise com base em suas leituras de Aristóteles, Arendt e Foucault. Expõe-se em sua reflexão certa distinção com os dois últimos, por um lado, e com o primeiro por outro. Se, de certa forma, Agamben tende a encontrar na modernidade a significativa mudança no que se refere à dupla existência pela qual o homem se apresenta sob o poder soberano, ele busca estabelecer que essa mudança tem fortes indícios já postos em momentos anteriores do mundo ocidental. Partindo, assim, de uma reflexão sobre bíos e zoè, Agamben insiste que já na Grécia antiga a relação da vida nua (zoè) e vida política (bíos) já se manifesta pela exclusão inclusiva. A zoè existe em e pela polis, que é seu fim final, não sendo assim totalmente separada, apartada e ausente de relação com a polis, senão que se relaciona com ela por meio da Cont.
} 
exceptio já estando presente nessa reflexão, para Agamben essa estrutura consubstancial à política ocidental adquire novos contornos no mundo moderno, principalmente se considerarmos o que esse pensador chama de paradoxo da soberania. De que se constitui esse paradoxo? Ora, a exceção não é uma simples exclusão, mas é constitutiva da regra geral, faz parte dela na forma mesma da exceção; e, assim, se põe como a confirmação da própria regra. Nesse caso, é por meio da suspensão da norma que a exceção se efetiva: é na suspensão da regra geral que a exceção (como exclusão da regra geral) se põe como regra e com esta se relaciona (ainda que na forma de exceção, de exclusão). A exceção pode ser considerada fora da lei geral, mas nem por isso isenta de normatividade e de legitimidade legal. É por isso que, para Agamben, o "particular 'vigor' da lei consiste nessa capacidade de manter-se em relação com uma sua exterioridade" - e, neste caso, uma relação de exterioridade com a própria suspensão de si como lei. "Chamemos relação de exceção", propõe Agamben (Idem, p. 26), "a esta forma extrema da relação que inclui alguma coisa unicamente através de sua exclusão" ${ }^{5} \mathrm{O}$ caso excepcional confirma a regra exatamente à medida que mantém com ela essa relação de exterioridade e sua realização como caso que está fora da regra não significa a invalidação nem sua nem da própria norma; ele efetiva não a supressão da norma, mas a sua própria confirmação através de sua suspensão.

No estado de exceção, a exceptio se transpõe para a rela-

exclusão.

${ }^{5}$ A esse propósito, Gilberto Bercovicci (2004, p. 66-67) comenta que a "exceção é o caso excluído da norma geral, mas não está fora da relação com a norma. [...]Há, portanto, uma distinção entre a norma e a sua aplicação: a aplicação da norma é suspensa, mas a norma, enquanto tal, permanece". 
ção entre vida e direito, o que não é senão o modo de aparecer da relação entre vida e Estado, entre vida (zoé) e forma de vida (bios) em uma dada situação histórica. Dentro dessa perspectiva, o que seria então o estado de exceção? E o que significa dizer que o campo é o modo de aparecer ampliado deste estado de exceção, o modo de sua efetivação normal? Para compreender essas questões, é preciso que entendamos algumas categorias insistentemente mobilizadas por Agamben em suas reflexões: indeterminação, indiferenciação, indiscernibilidade, relação paradoxal de exclusão e inclusão, direito e fato, dentro e fora. Esta é talvez uma das mais características novidades apresentadas pelo pensador de o Homo Sacer em suas obras, com o objetivo de escapar do princípio da identidade e, ao mesmo tempo, da contradição dialética. São essas referências categoriais que caracterizam, segundo ele, de um modo bem geral, as estruturas topológicas da relação entre o Estado e o direito que se apresentam numa aparente ambiguidade em sua configuração moderna. Com base nessa representação topológica da estrutura da soberania (e, em geral, dos fenômenos jurídicopolíticos que discute), Agamben (2004, p. 39) afirma que o "o estado de exceção não é nem exterior nem interior ao ordenamento jurídico e o problema de sua definição diz respeito a um patamar, ou uma zona de indiferença, em que dentro e fora não se excluem, mas se indeterminam”. O que ocorre no estado de exceção é, segundo a reflexão agambeniana, a suspensão da norma, que não implica aqui sua "abolição", mas a possibilidade de sua permanência e efetividade, ainda que na forma de sua suspensão. Já o "campo é o espaço desta absoluta impossibilidade de decidir entre fato e direito, entre norma e aplicação, entre exceção e regra, que, entretanto, decide incessantemente sobre 
eles" (AGAMBEN 2001, p. 180). Em outras palavras, para Agamben (Idem, p. 177), "no campo a quaestio iuris não é mais absolutamente distinguível da quaestio facti": "[...] é um híbrido de direito e de fato, no qual os dois termos tornaram-se indiscerniveis".

O que ocorre no estado de exceção (e, portanto, também no campo, à medida que neste a exceção se torna regra) é a instauração de uma "zona de anomia [que] não é (ou, pelo menos, não pretende ser) destituída de relação com a ordem jurídica" (AGAMBEN 2004, p. 39). Esta zona de anomia (que não é absolutamente ausência de norma), que é zona de indiferença, de indeterminação, é, como quero insistir, a chave para a compreensão dessa aparente ambiguidade do estado de exceção nos termos de Agamben. É uma ambiguidade aparente - e, na verdade, um paradoxo justamente porque em sendo a suspensão da norma o que o caracteriza, essa suspensão somente pode ser a realização da própria norma.

A questão é que se o estado de exceção não pode ser pensado na forma de uma anormalidade, não pode ser também, por outro lado, considerado como uma situação de plena efetivação da norma. O estado de exceção é uma situação que se encontra ao mesmo tempo fora da normalidade e simultaneamente estabelece com ela uma relação de excepcionalidade, aplicando-se como norma, como seu modo de aparecer (excepcional). Isso se expressa de um modo geral, por exemplo, nos documentos constitucionais em que a legislação instituída apresenta sua suspensão como uma potência própria da norma, prevista, garantida e legitimada por ela. ${ }^{6}$

\footnotetext{
${ }^{6}$ A polêmica questão da possiblidade do aparato jurídico-legal conter ou não em sua letra o estado Cont.
} 
O problema aqui, e como tal ele já aparece nas reflexões de autores como Carl Schimitt, é: qual(is) situação(ões) seria(m) essa(s) que exigiria(m) a efetivação deste estado de exceção, ou seja, a suspensão da norma, do direito, e quem então poderia decidir sobre isso. Para Schmitt, autor que se impõe como central à reflexão agambeniana sobre o estado de exceção e a teoria da soberania, é inquestionavelmente a decisão soberana o fundamento do estado de exceção e é, portanto, o poder soberano que a toma (isto é, é ele quem decide sobre o estado de exceção e, consequentemente, sobre a normalidade). Para Paulo Arantes (2007, p. 41), está justamente aí a importância dessa definição schmittiana do poder soberano: "voltar a lembrar - infelizmente à sombra de um autor maldito -, contra a maré do normativismo jurídico que hoje nos ofusca como uma segunda natureza, que toda lei tem, por assim dizer, seu lado de fora e que esse exterior, por sua vez, não é, nem pode ser, limitado por lei alguma [...]". Conforme à concepção schmittiana, Agamben compreende a política estatal contemporânea como empoderamento pelo Estado da vida destituída de toda forma, como vida nua, e a adoção cada vez mais comum do estado de exceção, de medidas excepcionais como técnicas de governo. Digo que é conforme à concepção schmittiana porque, nesse contexto de exceção, se apresenta para Agamben a identidade essencial da soberania já apontada

\footnotetext{
de exceção é, segundo Agamben, colocada no mesmo patamar do direito de resistência. Paira sobre essas duas instâncias reflexões que se posicionam ora favoráveis ora contrárias à inclusão das mesmas nos textos legais. "De fato, tanto no direito de resistência quanto no estado de exceção, o que realmente está em jogo é o problema do significado jurídico de uma esfera de ação em si extrajurídica. Aqui se opõem duas teses: a que afirma que o direito deve coincidir com a norma e aquela que, ao contrário, defende que o âmbito do direito excede a norma. Mas, em última análise, as duas posições são solidárias no excluir a existência de uma esfera humana que escape totalmente ao direito" (AGAMBEN 2004, p. 24).
} 
por Schmitt: a decisão soberana, ou seja, o soberano como aquele que tem a prerrogativa de decidir sobre a exceção, sendo precisamente essa prerrogativa o que o define como tal. O soberano decide a tempo e a hora, no calor e pelo clamor da emergência.

Ora, mas aí, junto com sua essência (o soberano é aquele que decide o estado de exceção), manifesta-se também sua necessidade essencial: a de salvar-se a si mesmo, em virtude do que sacrifica talvez aquilo que por muito tempo confundiu-se com ele, a saber, o direito, a normalização na forma do direito. Segundo Schmitt (2005, p. 30): "Diante de um caso excepcional o Estado suspende o Direito por virtude do direito à própria conservação". Como Arantes (2011, p. 222) afirma:

a exceção soberana [entra] em cena com todo o seu cortejo dramático de violência, segredo, razão incomensurável à compreensão ordinária dos governados, mas, sobretudo, em função de uma necessidade política maior - a salvação mesma do Estado -, a transgressão da forma jurídica por força de uma urgência extrema, uma necessidade de exceção enfim, uma conjuntura de emergência que requer do poder de Estado uma intervenção extraordinária, fora dos princípios do direito comum.

A necessidade essencial do soberano de se defender e a justificação da violência posta para essa defesa do soberano (ou da soberania), como já anunciou Foucault, ${ }^{7}$ é, portanto,

\footnotetext{
${ }^{7}$ Conforme Foucault (1999, p. 76), essa necessidade de defender-se do soberano ganha feições significativamente novas: "O direito de punir deslocou-se da vingança do soberano à defesa da sociedade", e justamente porque todo crime passa a ser crime contra a sociedade, "contra todo o corpo social". O referido autor também esclarece noutro lugar essa "autodefesa" do soberano: "Mas se foi um deles quem se levantou contra ele e infringiu suas leis, então, pode exercer um poder direto sobre sua vida: matá-lo a título de castigo [...] Essa morte, que se fundamentava no direito do soberano se defender ou pedir que o defendessem, vai aparecer como o simples reverso do direito do corpo social de garantir sua própria vida, mantê-la ou desenvolvê-la" (FOUCAULT 2007, p. 147-149).
} 
o que passa a conduzir o poder na política contemporânea. Talvez por isso exista a necessidade constante de se anunciar, alarmar, alardear sobre a condição de constante ameaça em que vive o povo, a sociedade, a "ordem (segurança) pública". Só assim se pode justificadamente "com mão mais forte" defendê-los, ainda que esta defesa signifique o sacrifício da própria democracia e, com ela, da própria vida tornada insacrificável e, por isso mesmo, matável (o homo sacer, ${ }^{8}$ na interpretação de Agamben). ${ }^{9}$

É preciso, portanto, refletir sobre como se apresenta o paradoxo da soberania numa situação histórica em que o estado de exceção se constitui na principal técnica de governo. Ora, a "exceção soberana (como zona de indiferença entre natureza e direito) é”, de acordo com a reflexão agambeniana, "a pressuposição da referência jurídica na forma de sua suspensão" (AGAMBEN 2001, p. 28), não mais a execução da lei na sua forma da normalidade, mas a sua relação com a exceção como possibilidade de sua efetiva execução. Começo, por isso, discutindo a definição, seguindo Giorgio Agamben, desse instituto que aparece atualmente como a grande técnica governamental dos Estados. Minha pretensão é, com base nesta análise, conduzir-me pa-

\footnotetext{
${ }^{8}$ Agamben se utiliza aqui do homo sacer para destacar a matabilidade da vida nua. A sua morte não assume, como na figura romana do homo sacer, qualquer dimensão jurídica (no sentido do castigo) ou religiosa (no sentido do sacrifício).

${ }^{9}$ Agamben destaca em $\mathrm{O}$ estado de exceção que a posição de alguns autores é a de que, em certos momentos, é necessário, em defesa da democracia, o seu sacrifício temporário. Uma das referências destacadas está a de Rossiter, que de modo expressivo afirma: "Nenhum sacrifício pela nossa democracia é demasiado grande, menos ainda o sacrifício temporário da própria democracia" (Rossiter 1948, p. 313, apud Agamben, G. Estado de exceção, p. 22.). Nesses termos, a suspensão da constituição e dos direitos se justifica pela defesa da própria democracia. Mas é aqui então que Agamben considera o aspecto subjetivo dessa decisão, à medida que se exige uma consideração de certas situações como ameaçadoras à democracia. Ele sustenta que "'democracia protegida' não é uma democracia e que o paradigma da ditadura constitucional funciona sobretudo como uma fase de transição que leva fatalmente à instituição de um regime totalitário” (Idem, p. 29).
} 
ra sua localização histórica, tentando pensar os elementos que caracterizam os momentos de sua aparição, quer isolado quer ampliado, destacando nesse percurso outras expressões que poderiam esclarecer o sentido e os efeitos da forma de ação excepcional, emergencial, dos atuais governos.

\section{SOBERANIA E ESTADO DE EXCEÇÃO}

Pensar a natureza do estado de exceção deve ter como ponto de partida a indagação sobre a aparente contradição: como pode o estado de exceção não estar nem no exterior nem no interior do ordenamento jurídico? Essa aparente contradição parece resolver-se justamente quando o autor apresenta o conceito de "zona de indiferença", porque, nesta, "dentro e fora não se excluem, mas se indeterminam". É essencial notar que aí se repõe a mesma relação de indiferença, indistinção ou indiscernibilidade que ocorre entre zoé e bios, vida e forma de vida. Mas não se trata apenas de uma reposição formal da relação topológica entre esses dois pares conceituais, pois é justamente porque vida nua e forma de vida assim se relacionam no estado de exceção sendo este o espaço da ampla manifestação da vida nua e de sua indeterminação com relação à sua forma política - que o estado de exceção mantém uma relação de indeterminação, indistinção ou indiscernibilidade com a normalidade jurídico-constitucional. Dizendo de outro modo, o que ocorre aqui é que a normalidade jurídico-constitucional mantém para com a vida, cujo desnudamento se expressa justamente como a suspensão de sua forma política, uma relação de exceção, que não é outra coisa senão uma relação de inclusão pela exclusão ou, o que é o mesmo, uma exclu- 
são inclusiva, uma exceptio. O que esta reflexão agambeniana quer ressaltar é que:

Longe de responder a uma lacuna normativa, o estado de exceção apresenta-se como a abertura de uma lacuna fictícia no ordenamento, com o objetivo de salvaguardar a existência da norma e sua aplicabilidade à situação normal. A lacuna não é interna à lei, mas diz respeito à sua relação com a realidade, à possibilidade mesma de sua aplicação. (AGAMBEN 2004, p. 48-49)

E é mais precisamente no momento em que se apresenta uma realidade em que fato e direito se indistinguem, à medida que semelhante realidade estabelece com a norma uma relação de indeterminação, que em decorrência se garante a vigência de uma situação em que a própria aplicação da norma se manifesta como sua não aplicabilidade. No dizer de Agamben (ibidem):

É como se o direito contivesse uma fratura essencial entre o estabelecimento da norma e sua aplicação e que, em caso extremo, só pudesse ser preenchido pelo estado de exceção, ou seja, criando-se uma área onde essa aplicação é suspensa, mas onde a lei, enquanto tal, permanece em vigor.

Não há, portanto, com a instauração do estado de exceção, por princípio, uma ruptura com a legalidade, com a norma. O que ocorre por outra feita é uma mudança significativa na relação entre norma e sua aplicação. $O$ estabelecimento do estado de exceção não necessariamente revoga a lei, não constitui uma quebra necessária da legalidade. Dito de outro modo ainda, o que se encontra nessa reflexão é que, para o pensador italiano, "a exceção é uma espécie de exclusão", isto é, "ela é um caso singular, que é excluído da norma geral. A norma se aplica à exceção desaplicando-se, retirando-se desta" (AGAMBEN 2001, p. 23). Todavia essa desaplicação da norma é a sua aplicação na forma da exceção. 
"Mas o que caracteriza propriamente a exceção", continua em outro passo Agamben (Idem, p. 25), "é que aquilo que é excluído não está, por causa disto, absolutamente fora de relação com a norma; ao contrário, esta se mantém em relação com aquela na forma da suspensão" - suspensão, vale reafirmar, que não significa abolição, supressão. Todavia, à medida que a norma é suspensa no estado de exceção ela o é na forma de uma aplicação de si mesma que instaura aí uma realidade em que ela se torna indiferente ao seu oposto, à "anormalidade", estando assim o vivente interposto neste limiar entre o normal e o excepcional. Seguindo a esse propósito, conduzindo-se por sua interpretação de Schmitt, Agamben (2004, p. 58) então afirma com base no jurista alemão: "O estado de exceção separa, pois, a norma de sua aplicação para tornar possível a aplicação. Introduz no direito uma zona de anomia para tornar possível a normatização efetiva do real”. Em seguida, Agamben então apresenta uma tese própria sobre a relação entre a suspensão, a ausência do direito e o próprio direito. Para ele: "Esse espaço vazio de direito parece ser, sob alguns aspectos, tão essencial à ordem jurídica que esta deve buscar, por todos os meios, assegurar uma relação com ele, como se, para se fundar, ela devesse manter-se necessariamente em relação com uma anomia” (IDEM, p. 79).

O ano de 1921 é apresentado por Agamben como o ano em que se observa a primeira aparição da teoria do estado de exceção na obra de Carl Schmitt - Die Diktatur (A ditadura). Na interpretação do pensador italiano, Schmitt "vê no estado de exceção precisamente o momento em que Estado e direito mostram sua irredutível diferença" (Idem, p. 47-48). Citando então o jurista alemão, Agamben (Idem, p. 48) continua: "no estado de exceção 'o Estado continua a 
existir, enquanto o direito desaparece"”. ${ }^{10}$ Para o pensador italiano, Die Diktatur e Politische Theologie (Teologia Politica, 1922) "descrevem com uma profecia, por assim dizer interessada, um paradigma (uma 'forma de governo' [Schmitt]) que não só permanece atual, como atingiu, hoje, seu pleno desenvolvimento" (AGAMBEN 2004, p. 53). Na primeira obra referida, escrita por volta de 1921, o "estado de exceção é apresentado através da figura da ditadura" (Ibidem); já na segunda, escrita em 1922, "ditadura e estado de sítio são substituídos por estado de exceção, Ausnahmezustand" (Idem, p. 54). Segundo Giorgio Agamben (Ibidem), nestes escritos, Schmitt intenta elaborar uma teoria que considera "a inscrição do estado de exceção num contexto jurídico". De acordo com a interpretação do pensador italiano, ao jurista alemão é clara a relação seja de suspensão, escape ou inascendência desta figura com a ordem jurídica, o direito; todavia, "para ele é essencial que se garanta uma relação com a ordem jurídica. [...] 'A ditadura, seja ela comissária ou soberana, implica a referência a um contexto jurídico'” (Ibidem).

Segundo Agamben (Idem, p. 13), justamente quando essa experiência do estado de exceção se amplia, isto é, desloca-se

de uma medida provisória e excepcional para uma técnica de governo [é que] ameaça a transformar radicalmente - e, de fato, já transformou de modo muito perceptível - a estrutura e o sentido da distinção tradicional entre os diversos tipos de constituição. $\mathrm{O}$ estado de exceção apresenta-se, nessa perspectiva, como um patamar de indeterminação entre democracia e absolutismo.

Quando o estado de exceção alcança o patamar de uma

${ }^{10}$ Cf. também em Schmitt, 2005, p. 30. 
indistinção com a norma, se amplia e se manifesta para além de uma situação extrema e se confunde com atos de governamentalidade, ${ }^{11}$ a democracia tende a se conduzir para um limiar em que se confunde com o totalitarismo; e isso ocorre justamente porque caracterizam as medidas excepcionais próprias ao estado de exceção a inobservância da norma, do direito, como tais, e a sua suspensão pelo poder soberano, mesmo na forma da normalidade. ${ }^{12}$ Nesse caso a decisão soberana assume o lugar que seria essencialmente do direito, dos institutos normativos e das instituições jurídico-políticas na democracia. Considere-se, a esse propósito, que, como observa Agamben (Ibidem), "uma das características essenciais do estado de exceção - a abolição provisória da distinção entre poder legislativo, executivo e judiciário - mostra, aqui, sua tendência a transformar em prática duradoura de governo".

E isso ocorre exatamente à medida que a vida nua toma o centro do poder político moderno e, mais precisamente, no momento em que esta tomada da vida pelo poder chega ao seu ápice. "No mesmo passo em que se afirma a biopolítica, assiste-se, de fato, a um deslocamento e a um progressivo alargamento, para além dos limites do estado de exceção, da decisão sobre a vida nua na qual consistia a soberania” (AGAMBEN 2001, p. 128). A suspensão da norma, a excepcionalidade da decisão soberana, torna-se cada vez mais o paradoxo da política contemporânea. $\mathrm{O}$ estado

\footnotetext{
${ }^{11}$ No sentido foucaultiano, isto é, como técnica de governo sobre os homens, que se verifica completamente na atualidade, sob o paradigma da segurança. Cf. FOUCAULT (2009).

12 "A Primeira Guerra Mundial - e os anos seguintes - aparece, nessa perspectiva, como o laboratório em que se experimentam e se aperfeiçoaram os mecanismos e dispositivos funcionais do estado de exceção como paradigma de governo. Uma das características essenciais do estado de exceção - a abolição provisória da distinção entre poder legislativo, executivo e judiciário - mostra, aqui, sua tendência a transformar-se em prática duradoura de governo" (Idem, p. 19).
} 
de exceção tende a confundir-se - e, na verdade, já o fez com o nómos do mundo moderno. E o que legitima esta situação de uma normal-excepcionalidade é, como aponta o pensador italiano, "a radical transformação da política em espaço da vida nua (ou seja, em um campo)", que, como tal, "legitimou e tornou necessário o domínio total" (Idem, p. $126)^{13}$ - sobre a vida. Como ele explica noutro lugar:

O nascimento do campo em nosso tempo surge então, nesta perspectiva, como um evento que marca de modo decisivo o próprio espaço político da modernidade. Ele se produz no ponto em que o sistema político do Estado-nação moderno, que se fundava sobre o nexo funcional entre uma determinada localização (o território) e um determinado ordenamento (o Estado), mediado por regras automáticas de inscrição da vida (o nascimento ou nação), entra em crise duradoura, e o Estado decide assumir diretamente entre as próprias funções os cuidados da vida biológica da nação (Idem, p. 181).

Ora, o que ocorre com o estado de exceção é que ele se constitui como um espaço, localização, em que a norma é permanentemente suspensa. Nele a exceção é a regra, e a suspensão da norma, o normal. Mas o que se extrema em nossos dias é justamente essa localização que se torna agora não localizável, não determinada espacialmente. No estado de exceção posto como espaço de suspensão da norma, e mais precisamente, no seu momento de extensão e ampliação, apresenta-se como característica justamente essa imprecisa localização dele. Melhor dizendo, a localização não precisa estar definida. $\mathrm{Na}$ terra de ninguém que caracteriza o estado de exceção, como o espírito de Deus que pairava sobre a face das águas antes da criação do mundo e do ho-

\footnotetext{
${ }^{13}$ Noutra passagem, Agamben diz ainda que "o campo, como puro, absoluto e insuperado espaço biopolítico (e enquanto tal fundado unicamente sobre o estado de exceção), surgirá como o paradigma oculto do espaço político da modernidade” (Idem, p. 129).
} 
mem, assim paira o poder soberano que decide. Sobre os mais diversos espaços em que se encontra a vida, nesta terra sem forma e vazia, reina o poder soberano.

"Somente porque em nosso tempo a política se tornou integralmente biopolítica, ela pôde constituir-se em uma proporção antes desconhecida como política totalitária” (Idem, p. 126), na qual a experiência do campo aparece como o modelo, como paradigma do mundo moderno. E o que se observa nessa tendência é que o que inicialmente assume um patamar localizável naquela imagem "clássica” do campo de concentração, agora tende cada vez mais a extrapolar não apenas no sentido de uma ordem (Ordnung) ilocalizável, indeterminável, mas também de um território (Ortnung) igualmente desconhecido, no sentido de não necessariamente delimitável. $\mathrm{O}$ campo aparece, pois, conforme a compreensão de Agamben, "como a matriz oculta, o nómos do espaço político em que ainda vivemos" (Idem, p. 173).

Contudo, para o pensador italiano, não se trata aqui de uma mera "reclusão": dizer que o campo aparece como paradigma do poder político contemporâneo, e que o que se produziu no campo o extrapola, está longe de significar a colocação dos indivíduos em qualquer espaço isolado tal como ocorreu então. Embora se possa identificar uma amplitude dos espaços de reclusão, sejam penitenciários sejam de modelos concentracionários os mais diversos, ${ }^{14}$ esta não é a principal marca deixada pelo campo. $\mathrm{O}$ que caracteriza a

\footnotetext{
${ }^{14}$ Citem-se aqui, por exemplo, os campos ou "centros fechados", como os chama Paulo Arantes numa retomada de Jean-Claude Paye (La fin de l'État de Droit: la lutte antiterroriste de l'état d'exception à la dictature), característicos da atual política europeia, "onde são depositados os estrangeiros em situação irregular, rigorosamente pessoas submetidas a um 'direito de exceção de ordem puramente administrativa"” (ARANTES 2011, p. 216).
} 
experiência política contemporânea, no que ela se apropria da experiência do campo, é justamente o fato de aquela, tal como este, ser "espaço de exceção, no qual o nexo entre localização e ordenamento é definitivamente rompido"; e é esta ruptura que, segundo Agamben, "determinou a crise do velho 'nómos da terra"' (AGAMBEN 2001, p. 27).

Aliás, "estar-fora e, ao mesmo tempo, pertencer: tal é a estrutura topológica do estado de exceção”, segundo Giorgio Agamben. Este é, a propósito, o significado da sua categoria de limiar. Como tal, o estado de exceção mantém uma relação de pertencimento com a normalidade estando fora dela. Justamente sobre isso, Schmitt (2005, p. 30) advertira: "O estado excepcional é sempre coisa distinta da anarquia e do caos, em sentido jurídico sempre subsiste uma ordem, embora essa ordem não seja jurídica". ${ }^{15}$ Nesse mesmo sentido, Agamben (2001, p. 23) afirma que "a exceção é verdadeiramente, segundo o étimo, capturada fora (ex-capere) e não simplesmente excluída” do ordenamento jurídico. E, por isso mesmo, o campo é "um pedaço de território que é colocado fora do ordenamento jurídico normal, mas não é, por causa disso, simplesmente um espaço externo" (Idem, p. 176-177).

\footnotetext{
${ }^{15}$ Ao analisar a posição de Creonte sobre o enterro de seu sobrinho na Antígona, de Sófocles, Diogo Pires Aurélio considera que a decisão tomada pelo novo governante de Tebas se mantém alinhada à "necessidade": mesmo essa decisão não tendo relação com qualquer norma anterior, não se pode considerá-la simplesmente descumprimento, mas uma suspensão que não altera, de modo algum, o andamento normal da lei. É neste sentido então que ele a considera como exceção: "A exceção, efetivamente, não configura aqui um qualquer momento de anarquia. Apesar de não poder deduzir-se de nenhuma norma anterior e, deste modo, assentar por inteiro na intuição e na vontade de Creonte, a ordem em que a exceção se materializa dá-se ainda sob a forma de lei, e de uma lei com força bastante para fazer calar, por um instante que fosse, as leis e costumes imemoriais" (AURÉLIO 2002, p. 69).
} 


\section{A ESTRUTURA PARADOXAL DA SOBERANIA E DO DIREITO}

Considerado assim o campo, nota-se que sua plena realização pode dar-se - e desse modo se manifesta plenamente na contemporaneidade - sem uma determinação espacial específica, sem constituir-se numa organização territorial delimitada, ou seja, um espaço fisicamente localizável. Além disso, a sua própria execução, ainda que na forma da excepcionalidade, já não pode ser pensada como uma ação fora da relação com a norma. Mesmo na forma da suspensão da norma, o estado de exceção não pode efetuar-se senão por sua necessária relação com ela. Se, antes, a excepcionalidade se manifestava como possibilidade de confirmação da regra, a exceção, hoje, em sua indistinção com o caso normal, confirma-se a si mesma. Como explicara Schmitt (2005, p. 30): "O normal nada prova; a exceção, tudo; não apenas confirma a regra, senão que esta vive daquela”. Daí deriva Agamben (2001, p. 27): “A relação de exceção exprime assim simplesmente a estrutura originária da relação jurídica”. Agora, a indiferença entre norma e exceção não mais se põe na forma de uma situação excepcional, mas a própria exceção se constitui como a estrutura originária da política contemporânea. Ou, noutros termos, em nossos dias, demonstra-se que "[...] a exceção é a forma originária do direito” (Idem, p. 34) que extrapola ao próprio direito.

Para Agamben (2004, p. 42), pensar o estado de exceção moderno significa pensá-lo enquanto "uma tentativa de incluir na ordem jurídica a própria exceção, criando uma zona de indiferenciação [um limiar] em que fato e direito coincidem”. Todavia, é preciso insistir nas perguntas:

Se o que é próprio do estado de exceção é a suspensão (total ou par- 
cial) do ordenamento jurídico, como poderá essa suspensão ser ainda compreendida na ordem legal? Como pode uma anomia ser inscrita na ordem jurídica? E se, ao contrário, o estado de exceção é apenas uma situação de fato e, enquanto tal, estranha ou contrária à lei, como é possível o ordenamento jurídico ter uma lacuna justamente quanto a uma situação crucial? E qual é o sentido desta lacuna? (Idem, p. 39).

Como ponto de partida para a reflexão dessas questões, Agamben (Idem, p. 12) apresenta a teoria do estado de exceção enquanto "condição preliminar para se definir a relação que liga e, ao mesmo tempo, abandona o vivente ao direito". Segundo ele, a excepcionalidade adquire novas dimensões na experiência política contemporânea, ou ainda, constitui-se como aquilo que caracteriza de modo mais imanente a experiência política moderna. Isto porque "as medidas excepcionais encontram-se na situação paradoxal de medidas jurídicas que não podem ser compreendidas no plano do direito, e o estado de exceção apresenta-se como a forma legal daquilo que não pode ter forma legal" (Idem, p. 11-12).

O sentido desta discussão encontra seu desaguar no esforço de Agamben em esclarecer sobre essa característica do estado de exceção de estar ao mesmo tempo dentro e fora da lei. E, mais precisamente, quando ele procura estabelecer uma reflexão sobre a relação da lei com sua aplicação:

O estado de exceção é, nesse sentido, a abertura de um espaço em que aplicação e norma mostram sua separação e em que uma pura força de lei ${ }^{16}$ realiza (isto é, aplica desaplicando) uma norma cuja

\footnotetext{
${ }^{16}$ Em sua obra Agamben utiliza essa expressão força de lei marcada com um X na palavra lei. Esse $\mathrm{X}$ demarca a posição do autor com relação a uma força tal como se apresenta no estado de exceção, e que é na verdade a força de sua sustentação, que está para além da forma lei, mantendo com ela, todavia, certa relação. Não se pode assim simplesmente falar de uma força retirando-se o restante da expressão de lei; por outro lado, também não seria o mais adequado falar de força de lei como se esta estivesse no mesmo patamar de legalidade jurídica. No caso deste trabalho, por Cont.
} 
aplicação foi suspensa. Desse modo, a união impossível entre norma e realidade, e a consequente constituição do âmbito da norma, é operada sob a forma da exceção, isto é, pelo pressuposto de sua relação. Isso significa que, para aplicar uma norma, é necessário, em última análise, suspender sua aplicação, produzir uma exceção. Em todos os casos, o estado de exceção marca um patamar onde lógica e práxis se indeterminam e onde pura violência sem logos pretende realizar um enunciado sem nenhuma referência real (AGAMBEN 2004, p. 63).

Neste caso, segundo nosso pensador italiano, o estado de exceção assume a forma do iustitium, figura do Direito Romano que "significa literalmente 'interrupção, suspensão do direito' [...] (se diz quando o direito para, como [o sol no] solstício)" (Idem, p. 68). Desse modo, "aquele que age durante o iustitium, não executa nem transgride, mas inexecuta o direito" (Idem, p. 78). Com referência em sua pesquisa genealógica, Agamben apresenta as teses sobre o iustitium, que, para ele, está na base fundamental da compreensão do estado de exceção moderno. Ele o explica do seguinte modo: "Implicava, pois, uma suspensão não apenas da administração da justiça, mas do direito enquanto tal" - daí por que "é o sentido desse paradoxal instituto jurídico, que consiste unicamente na produção de um vazio jurídico, que se deve examinar aqui, tanto do ponto de vista da sistemática do direito público quanto do ponto de vista filosófico-político" (Idem, p.68). Não considerar essa figura tem sido um equívoco de muitos teóricos, segundo Agamben, já que para ele esse instituto se apresenta como uma chave na interpretação do estado de exceção, tal como se apresenta na contemporaneidade. E justamente porque "o

uma questão prática (técnica), substituo o X pelo travessão, mantendo, entretanto, o significado pretendido pelo referido pensador italiano. 
estado de exceção não se define, segundo o modelo ditatorial, como uma plenitude de poderes, um estado pleromatico do direito, mas sim, como um estado kenomatico, um vazio e uma interrupção do direito" (Idem, p. 75) aproximando-se assim do sentido da interrupção que se manifesta lá no iustitium. Precisamente por isso o autor do Homo Sacer chega à conclusão de que o "estado de exceção não é uma ditadura (constitucional ou inconstitucional, comissária ou soberana), mas um espaço vazio de direito, uma zona de anomia em que todas as determinações jurídicas - e, antes de tudo, a própria distinção entre público e privado - estão desativadas" (Idem, p. 78).

Destacando essa zona de anomia, "zona ilocalizável de indiferença ou de exceção” (AGAMBEN 2001, p. 27), como característica decisiva do estado de exceção na contemporaneidade, Agamben então tenta resolver o problema de sua aparente ambiguidade. Segundo o pensador italiano, "essa zona - onde se situa uma ação humana sem relação com a norma - coincide com uma figura extrema e espectral do direito, em que ele se divide em uma pura vigência sem aplicação (a forma de lei) e uma aplicação sem vigência: a força-da-lei" (AGAMBEN 2004, p. 93). A manifestação do estado de exceção como espaço anômico diz respeito exatamente àquela imagem de uma força de lei sem lei (que de acordo com sua análise deveria ser escrita: força-de-lei): "Tal força-de-lei, em que potência e ato estão separados de modo radical, é certamente algo como um elemento místico, ou melhor, uma fictio por meio da qual o direito busca se atribuir sua própria anomia” (Idem, p.61). O estado de exceção é, então, isso: um fato fora da lei, que, contudo, mantém-se 
em relação com ela; mais ainda: "como anômico fundamento da ordem jurídica” (Idem, p. 107). ${ }^{17}$

Essa ambiguidade essencial do estado de exceção aponta para uma identificação entre o soberano, acima do qual nada está, e a lei; e justamente aí se constitui o que Agamben chama de anomia do soberano, que se põe, dessa forma, vinculado com a ordem jurídica. É o que nosso autor identifica à teoria política helenística de nòmos émpsychos, a "lei viva" (ou ainda, vivente), segundo ele a forma arcaica de nossa moderna teoria da soberania. Para o pensador grego do período helenista Arquitas de Tarento, o soberano constitui-se num nòmos empsýchos (lei animada), em oposição ao àpsychos nómos (lei inanimada), significando, com isso, que sua relação com a lei não é passiva, não sendo dela apenas um administrador, mas propriamente um sujeito dela que, em contrapartida, não lhe está sujeito: "o rei era para defender a lei, mas não ser constrangido por ela" (the king was to uphold the law but not be bound by it) (GÜNTHER ET AL 2008, p. XVI). ${ }^{18}$

Por isso, para Agamben, no nòmos émpsychos se manifesta o conceito de "indefinibilidade": o "não-lugar absoluto." Essas expressões são associadas pelo pensador italiano à "ideia de uma força-de-lei", na qual a ausência da lei e sua vigência se relacionam, de modo que o ordenamento jurídico (atualmente constituído ou em potência no poder constituinte) se ponha igualmente numa relação com o es-

\footnotetext{
17 "Antes de assumir a forma moderna de uma decisão sobre a emergência, a relação entre soberania e estado de exceção apresenta-se sob a forma de uma identidade entre soberania e anomia. $\mathrm{O}$ soberano, enquanto lei viva, é intimamente anomos. Também aqui o estado de exceção é a vida secreta e mais verdadeira - da lei." (Ibidem).

${ }^{18}$ Segundo interpreta Fernández (2008, p. 49-67), essa teoria também teve uma versão judaica com Fílon de Alexandria, que, tendo em mente um "ideal de monarquia davídica", concebe Moisés como modelo perfeito e José como exemplo imperfeito desse ideal.
} 
tado de exceção. É uma dupla forma da lei - na vigência e na ausência, na aplicação e na suspensão - que é igualmente um duplo lugar que conduz ao não-lugar. É com base nessa dupla posição da lei, em que também sua força se apresenta separada de sua forma (situação expressa no sintagma "força-da-lei"), que Agamben pensa a realização do estado de exceção.

Abstract: Based on the categorical connection between the field and the state of exception, I propose to discuss on this article Giorgio Agamben's conception of the state of exception in its paradoxical relationship with the law, a relationship which is proper to the paradoxical structure of sovereignty. The field is to the Italian thinker the experience which is able to clarify the paradoxical dimension of the state of exception because it expresses itself at the same time as inside and outside the legal system. On the contemporary experience the state of exception is no longer characterized as an exceptional experience, but it has become the norm. Based on this, we want to present the dialog between Agamben and Carl Schmitt, in order to reflect on the condition of the state of exception to present itself as anomy, whilst continuing to establish with the law a necessary relationship, even in the form of suspension.

Keywords: Field; Sovereignty; State of Exception; Power-of-Law.

\section{REFERÊNCIAS}

AGAMBEN, G. Estado de Exceção. Trad. Iraci D. Poleti. São Paulo: Boitempo, 2004.

- Homo Sacer. O poder soberano e a vida nua I. Trad. Henrique Burigo. Belo Horizonte: Editora UFMG, 2002.

ARANTES, Paulo. Extinção. São Paulo: Boitempo, 2007.

. O alarme de incêndio no gueto francês: uma introdução à Era da Emergência. In: Discursos sediciosos: Crime, Direito e Sociedade, Ano 15, nos. 17/18 (2010). Rio de Janeiro: Editora Revan, 2011. 
AURÉliO, Diogo Pires. "Caso de necessidade" na ordem política. In: Cad. Hist. Fil. Ci., Campinas, Série 3, v. 12, n. 1-2, p. 65-87, jan.-dez. 2002. Disponível em: http://www.cle.unicamp.br/cadernos/pdf/Diogo\%20Pires\% 20Aurelio.pdf (acesso em 08.12.2012).

BERCOVICI, G. Constituição e estado de exceção permanente. Rio de Janeiro: Azougue, 2004.

LEVI, P. É isto um homem? Trad. bras. Luigi del Re. Rio de Janeiro: Rocco, 1988.

LOTTES, Günther; Medijainen, Eero; Sigurðsson, Jon Viðar. Introduction. Making, using and resisting the law in European history / edited by Günther Lottes, Eero Medijainen, Jón Viðar Sigurðsson. - Pisa: Plus-Pisa University Press, 2008, p. XVI. http://ehlee.humnet.unipi.it/books3/1/00a_INTRODUCTI ON.pdf (acesso em 25.11.2012).

FERNÁNDEZ, Martín González. Nòmos émpsychos. El Tratado De Iosepho de Fílon de Alejandría. In: Revista española de filosofia medieval, 15 (2008).

SCHMITT, C. Teología política. Trad. arg. Francisco Javier Conde. Buenos Aires, Argentina: Editorial Struhart \& Cía., 2005. 